\title{
The training of child psychiatrists in Thailand
}

\author{
L. B. Bartlet and Vanpen Boonyaprakob
}

In most Asian countries child psychiatry is still in its infancy and the few specialists operating in this field have received their training overseas, usually in Europe or the USA. There is a perceived need for more expertise in child mental health and the unsatisfactory solution often adopted is for psychiatrists trained in adult work to move in and learn from experience.

This is not the situation in Thailand. Child psychiatry is recognised by the Ministry of Health and the Thai Medical Council as a fully fledged subspeciality and in 1990 an approved training programme was set up. In this respect. Thailand is well ahead of its neighbours. This may be, in part, a result of the relatively high profile of child psychiatry. The Vice-President and Registrar of the College of Psychiatrists in Thailand are both child psychiatrists. Child mental health issues are popular on television and radio and one or two of the senior child psychiatrists are media figures.

After their six-year training is completed, young doctors are expected to work for three years in rural areas or pay back their training costs. For a number of years graduates intending to enter psychiatry were excused from rural service because of the shortage of psychiatrists. Although this is no longer the case, the Medical Council may reinstate this exemption.

In 1972 a milestone was passed when the Thai Medical Council established a three-year residency programme in general psychiatry. This includes a three-month placement in a child psychiatric department wherein a broadly based programme is provided which covers family work, individual play and behavioural therapies, psychopharmacology and counselling for parents and schools.

What may be termed the foundation group of That child psychiatrists included a number of distinguished and cnarismatic practitioners, six of whom trained in America, one in Australia and one in the UK. Their pioneering endeavours were valued by their colleagues in general psychiatry. So the climate was right for the inception of the child psychiatry scheme in 1990.

\section{The Child Psychiatric Training Programme}

Residency programmes are generally for three years. For the future child psychiatrist there are two possibilities: (a) a three year residency in child psychiatry, or (b) three years general plus two years child psychiatry - an arrangement that is considered too long and may be replaced by a two plus two years programme.

Trainees are given experience in out-patient and in-patient work, which includes psychotherapy. In-patients under twelve years of age are seen in paediatric wards and adolescents in psychiatric departments - there is an adolescent unit in Somdet Chaopraya Hospital. Community experience is gained in normal and special schools and in a number of non-governmental agencies (such as sexual abuse teams) that appreciate the support of the child psychiatric services. Paediatric links are strong and there is a four-month placement, two months in general paediatrics and two in the neurological/developmental field. Infant mortality in Thailand has fallen and in its train has brought a greater awareness of the behavioural, emotional and neurological sequelae of perinatal stress. There are short placements to cover mental handicap and autism. Two weeks are spent studying delinquency and court work.

Three medical schools associated with Mahidol and ChulalongKorn Universities are involved; these are Siriraj, Ramathibodi and ChulalongKorn Hospitals all located in Bangkok. For lectures, seminars and interhospital conferences trainees from the three centres come together. Individual supervision is provided on a regular basis by senior psychiatrists and clinical psychologists though this makes considerable demands on their time. Psychotherapy (including play, individual, family and group) features strongly in the curriculum.

Examinations, written, clinical and oral are held at the end of each year. Before the final examination students must present evidence of successfully completing at least one research project. Before obtaining the Diploma in Child 
and Adolescent Psychiatry success has to be achieved in four written papers, two case reviews and an oral examination.

Eleven child psychiatrists have been trained through this programme bringing the total number in the subspeciality to 25 . There are approximately two hundred general psychiatrists in the country. On completion of training the majority take up staff posts in government hospitals. In recent times only one has gone to work in a private hospital.

\section{A child peychiatry course for paedia- tricians}

The need for child psychiatric expertise in Thailand is such that one of the authors (VPB) decided to offer a programme for young paediatricians interested in behavioural and psychosomatic aspects of their field. A Fellowship in child psychiatry was established. The paediatricians spend nine months in general psychiatry followed by 15 months participating in the child psychiatry programme. Thereafter they are expected to continue practising child psychiatry as part of their paediatric work for a further three years. They are then eligible to apply for certification. Their applications are considered by the appropriate committee. So far, ten paediatricians have obtained this Fellowship, greatly strengthening the mental health skills of the paediatric departments wherein they operate.

\section{Comment}

In the developing world where children form a high proportion of the total population the need for better child mental health services (World Health Organization, 1977) and more trained child psychiatrists, (Mbwambo et al, 1992) is recognised. Yet few developing countries have prioritised the issue. As described above, Thailand has moved faster than its neighbours in this respect.

At a time when, following the 'Calman' Report (DOH, 1993), the training of psychiatrists in the UK is under review it is interesting to note that governmental and professional organisations in Thailand are facing similar problems. The fact that the Thai training programme for child psychiatrists is longer than for general psychiatrists is unsatisfactory. But shortening the programme drastically would result in inadequately trained specialists leading child mental health teams with wider and more complex burdens than is usually the case in the West. Whatever the outcome, it is heartening to see that child psychiatry in Thailand is developing on professionally sound foundations.

\section{References}

DePARTMENT OF HEALTH (1993) Hospital Doctor: Training for the Future. The Report of the Working Group on Spectalist Medical Training. London: Department of Health.

MBWAMBO, J., APPLEBY, L. \& GATER, R. (1992) The training of psychiatrists for the developing world: Psychiatric Bullettn. 16, 352-354.

WORLD HEALTH ORGANIZATION (1977) Child Mental Health and Psychosoctal Development. Technical Report No. 617. Geneva: WHO.

*L. B. Bartlet, Honorary Consultant Psychiatrist, Paediatric Department, Southampton General Hospital, Southampton SO16 6YD; and Vanpen Boonyaprakob, Senior Child Psychiatrist, Striraj Hospital, Mahidol University, Bangkok, Thailand

*Correspondence 